\title{
Association between alendronate and atypical femur fractures: a meta-analysis
}

\section{Lu Liu, Chunyan Li, Peng Yang, Jian Zhu' ${ }^{1}$, Dongmei Gan², Le Bu, Manna Zhang, Chunjun Sheng, Hong Li and Shen Qu}

Department of Endocrinology, Shanghai Tenth People's Hospital, Tongji University School of Medicine, 301 Yanchang Middle Road, Shanghai 200072, China

${ }^{1}$ Department of Internal Medicine, Shanghai Dachang Hospital, Shanghai 200442, China

${ }^{2}$ Department of Paediatrics, Ningbo Women and Children's Hospital, Ningbo, Zhejiang Province 315012, China

\author{
Correspondence \\ should be addressed \\ to $\mathrm{H} \mathrm{Li}$ \\ Email \\ lihong_endo@tongji.edu.cn
}

\begin{abstract}
Alendronate (ALN) is a commonly used drug for the treatment of osteoporosis. Atypical femur fractures (AFFs) have been associated with long-term use of ALN and have recently become the subject of considerable attention as ALN use increases. This meta-analysis aimed to determine the relationship between ALN and AFF. The Embase, PubMed, and Cochrane library databases were searched for relevant studies published before November 6, 2014. Studies clearly reporting the relationship between ALN and AFF were selected for our analysis. From these results, the relationship between ALN and AFF was analyzed. Weighted mean differences were calculated using a random-effects model. Five studies were included in this meta-analysis. The results revealed that the use of ALN will not increase the risk of AFF in short term $(P>0.05)$, but there will be a risk of AFF $(P<0.05)$ with long-term ( $>5$ years) use of ALN. These findings indicate that long-term use of ALN is a risk factor for AFF and that more attention should be paid to the clinical applications of ALN.
\end{abstract}

\section{Introduction}

Osteoporosis is a major metabolic bone disease that affects 44 million Americans or 55\% of the population at the age of 50 years or older. Out of them, ten million individuals already have the disease while 34 million more are at an increasingly high risk of osteoporosis (1). Though osteoporosis is often thought of as an older person's disease, it can strike at any age. The disease causes a significant amount of morbidity and mortality in patients and is often diagnosed after a fracture occurs. Current medications used to treat osteoporosis include bisphosphonates, raloxifene, calcitonin, and hormone replacement therapy (2). Bisphosphonates are a class of

\author{
Key Words \\ - alendronate \\ - atypical femur fractures \\ - meta-analysis \\ - osteoporosis
}

widely prescribed drugs that are proven to be effective in reducing common bone fractures in people with osteoporosis and those at a high risk of fractures $(3,4,5)$.

Alendronate (ALN) is a potent oral bisphosphonate with a prolonged duration of action and is the most commonly prescribed bisphosphonate (6). The pharmacokinetics of ALN allow for a once-weekly regimen that leads to continued maintenance of bone mineral density for months to years after discontinuation (7). ALN could inhibit osteoclast-mediated bone resorption and normalize the rate of bone turnover to premenopausal levels. In both animal and human studies, administration

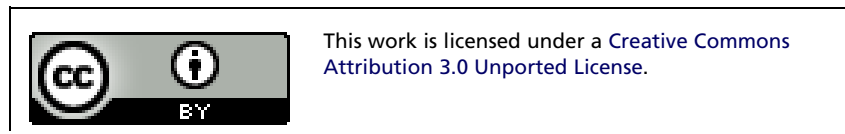


of ALN could increase bone mass and maintain histologically normal bone $(8,9,10)$. Bone et al. (11) found that clinical symptoms and indicators improved significantly with long-term use of ALN for elderly postmenopausal women with osteoporosis. However, results from a growing number of recent studies have indicated that bone turnover will be suppressed excessively with longterm use of ALN, which will lead to the occurrence of atypical femur fracture (AFF) (12). This study collected relevant literature on the use of ALN and the consequent incidence of AFF and utilized meta-analysis to clarify the relationship between ALN use and AFF occurrence to provide credible advice for clinicians.

\section{Methods}

\section{Literature retrieval}

The Cochrane library, PubMed, and Embase databases were searched to retrieve relevant studies published before November 6, 2014. The search criteria 'femoral fracture' or 'femur fracture' or 'hip fracture' or 'diaphyseal' or 'atypical fractures' and 'ALN' were used in text word searches, while the 'related articles' function was used to broaden the search. Reference lists of selected articles were also manually examined to find relevant studies not discovered during the database searches. Any observational or interventional studies that examined the relationship between ALN and AFF were selected. All titles, abstracts, and full papers of potentially relevant studies were assessed for eligibility based on predefined inclusion and exclusion criteria. Eligible papers included i) studies on the use of ALN and AFF that were published before November 6, 2014, ii) cohort studies to confirm osteoporosis in a population, iii) studies where the statistical indicator was AFF. Finally, relevant articles were examined to ensure that the diagnosis standards of AFF were consistent. When several reports from the same study were published, only the most recent or informative was included in our meta-analysis. The language was restricted to English.

\section{Data extraction}

Data extractions of all variables and outcomes of interest and assessment of methodological quality were performed independently by two readers. Any disagreements were resolved through discussion to reach a consensus. The methodological quality of the trials was evaluated using the assessment forms from the Agency for Healthcare Research and Quality.

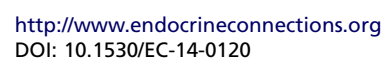

\section{Statistical analysis}

Statistical analysis was performed using the ReviewManager 5.0 Software (Cochrane Collaboration, Nordic Cochrane Centre, Copenhagen, Denmark). Continuous variables were analyzed using the weighted mean difference. $P$ values $<0.05$ were considered statically significant, and 95\% CIs were reported. Homogeneity was tested using the $Q$ statistic (significance level at $P<0.10$ ) and the $I^{2}$ statistic (significance level at $I^{2}>50 \%$ ). If the overall effects of multiple findings were consistent, the fixed-effects model was used; otherwise, the random-effects model was employed. The presence of publication bias was assessed by the visual inspection of a funnel plot.

\section{Results}

\section{Literature search}

The initial literature search retrieved 1108 relevant articles (duplicates were discarded). Of these articles, 1065 were excluded from our analysis for not investigating

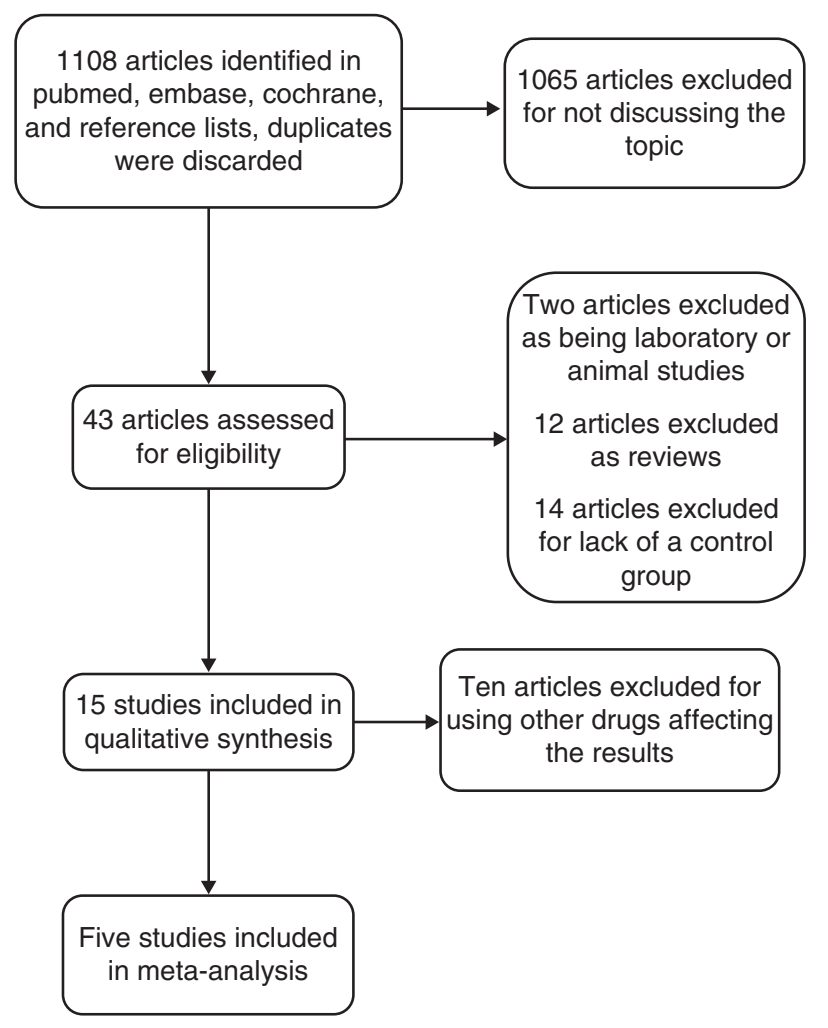

Figure 1

Search strategy flow diagram.

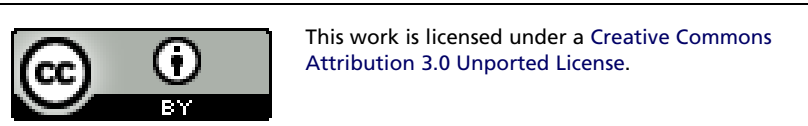


Table 1 Characteristics of the studies included in this research.

\begin{tabular}{|c|c|c|c|c|c|c|c|c|}
\hline Reference & $\begin{array}{l}\text { Research } \\
\text { on life }\end{array}$ & Study area & Study design & $\begin{array}{l}\text { Female } \\
\text { patients (\%) }\end{array}$ & Sample size & Age & $\begin{array}{c}\text { AFF } \\
\text { number }\end{array}$ & AFF type \\
\hline (13) & 1997-2005 & Denmark & Cohort study & 91.2 & 10374 vs 5187 & $\begin{array}{c}73.1 \pm 8.5 \text { vs } \\
73.1 \pm 8.5\end{array}$ & 76 & $\begin{array}{l}\text { Trochanter, } \\
\text { femoral shaft }\end{array}$ \\
\hline (14) & 1996-2005 & Denmark & Cohort study & 82.8 & $\begin{array}{c}158268 \text { vs } \\
39567\end{array}$ & $\begin{array}{c}69.8 \pm 11.6 \text { vs } \\
69.8 \pm 11.6\end{array}$ & 1049 & $\begin{array}{l}\text { Trochanter, } \\
\text { femoral shaft }\end{array}$ \\
\hline (15) & 2002-2007 & America & Cohort study & 84.3 & 45 vs 25 & 77.1 vs 69.4 & 20 & $\begin{array}{l}\text { Trochanter, } \\
\text { femoral shaft }\end{array}$ \\
\hline (16) & Unknown & America & Cohort study & 100 & 3223 vs 3236 & Unknown & 2 & $\begin{array}{l}\text { Trochanter, } \\
\text { femoral shaft }\end{array}$ \\
\hline (17) & 2001-2005 & Taiwan & Cohort study & Unknown & 6159 vs 5119 & Unknown & 61 & $\begin{array}{l}\text { Trochanter, } \\
\text { femoral shaft }\end{array}$ \\
\hline
\end{tabular}

the topic of interest. The abstracts were reviewed from the 43 remaining articles, and another 38 articles were excluded (two laboratory or animal studies, 12 reviews, 14 without a control group, and ten with other bisphosphonates). Therefore, five studies matched the selection criteria and were suitable for our meta-analysis $(13,14,15$, 16, 17). A flow-diagram for the selection of studies included in our meta-analysis is shown in Fig. 1. A total of 231203 patients (53134 experimental group and 178069 control group) were included in our analysis. The key characteristics of the included studies are summarized in Table 1 . Table 2 summarizes the methodological quality of the studies.

\section{Main analysis}

Figure 2 summarizes the outcome of our meta-analysis. Heterogeneity analysis was performed on the five papers, and the results indicated that heterogeneity was significant $\left(P<0.05, I^{2}=97 \%\right)$. Therefore, the randomeffects model was employed. The results were $\mathrm{RR}=3.23$, $95 \%$ CI $(0.88,11.84), P>0.05$ (Fig. 2), and the differences were not statistically significant. Among them, 5-year oral administration periods were considered in two studies $(13,14)$, and further stratified studies were conducted. Heterogeneity analysis was also performed on these two papers, and the results indicated that heterogeneity was not significant; therefore, the fixed-effects model was used

Table 2 The methodological quality of the studies included in this research.

\section{Criterion}

1. Defined the source of information (survey and record review)

2. Listed inclusion and exclusion criteria for exposed and unexposed subjects (cases and controls) or referred to previous publications

3. Indicated time period used for identifying patients

4. Indicated whether or not subjects were consecutive if not populationed-based

5. Indicated if evaluators of subjective components of study were masked to other aspects of the participants

6. Described any assessments undertaken for quality assurance purposes

7. Explained any patient exclusions from analysis

8. Described how confounding was assessed and/or controlled

9. If applicable, explained how missing data were handled in the analysis

10. Summarised patient response rates and completeness of data collection

11. Clarified what follow-up, if any, was expected and the percentage of patients for which incomplete data or follow-up was obtained

(13)
Yes
Yes
Yes
No
Unclear
Yes
Yes
Yes
Yes
Yes
Yes

http://www.endocrineconnections.org

DOI: 10.1530/EC-14-0120

\begin{tabular}{c}
\hline (15) \\
\hline Yes \\
Yes
\end{tabular}

\begin{tabular}{c}
\hline (16) \\
\hline Yes \\
Yes
\end{tabular}

\begin{tabular}{c} 
(17) \\
\hline Yes \\
Yes \\
Yes \\
Yes
\end{tabular}

No

Yes

Unclear

Unclear

Unclear

Unclear

Yes
Yes
Yes
Yes
Yes
Yes

Yes
Yes
Yes
Yes
Yes

Yes

Yes

Yes

Yes

Yes

Yes

Yes

Yes
Yes
Yes
Yes
Yes

No

Yes

Yes

Yes

Yes

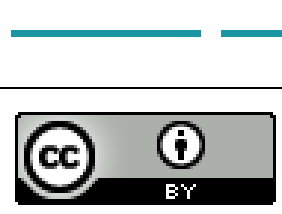

This work is licensed under a Creative Commons Attribution 3.0 Unported License. 


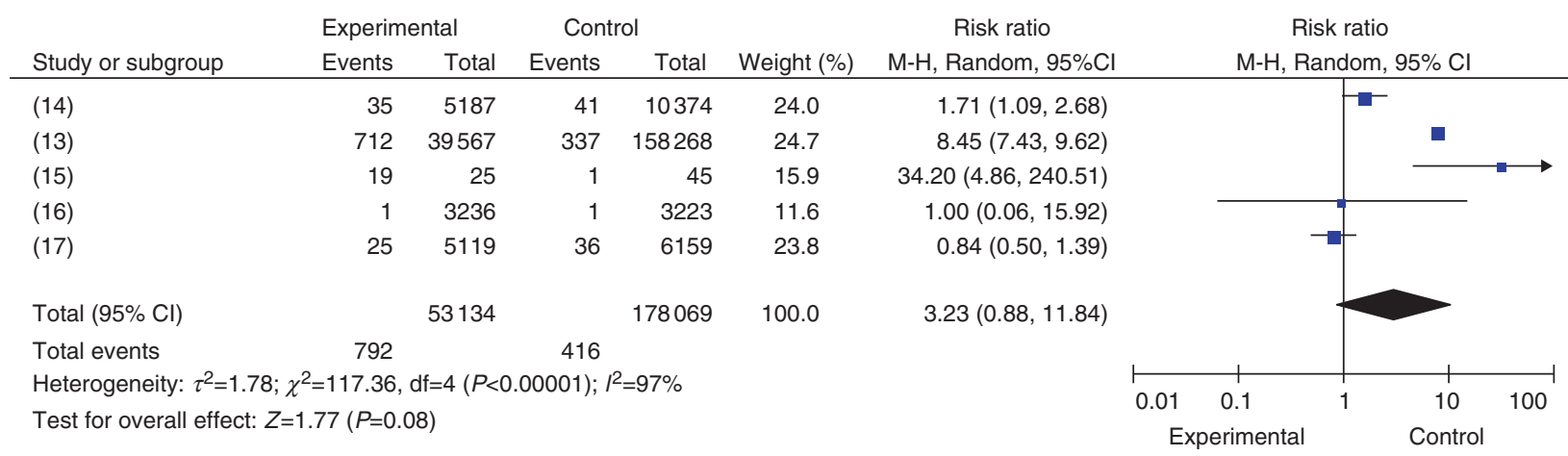

\section{Figure 2}

The risk of AFF for patients using ALN.

$\left(P=0.18, I^{2}=44 \%\right)$. The results were $\mathrm{RR}=2.55,95 \% \mathrm{CI}$ (2.26, 2.88), $P<0.05$ (Fig. 3), and the difference was statistically significant (as shown in Fig. 3).

\section{Discussion}

ALN belongs to the third generation of bisphosphonate drugs that could inhibit the activity of osteoclasts by physicochemically combining with the bone matrix and subsequently blocking the action of osteoclasts by inducing the secretion of a variety of cytokines. In addition, ALN can regulate the metabolism of calcium in vivo, prevent the loss of bone mass, and augment bone mineral density, all of which explain why ALN is the most widely used bisphosphonate. Bisphosphonates are the primary agents used to treat osteoporosis, metastatic bone malignancies, Paget's disease, multiple myeloma, and hypercalcemia in malignancy. Moreover, bisphosphonates are commonly used for prevention and treatment of a variety of other skeletal conditions, such as low bone density and osteogenesis imperfecta $(18,19)$.
$\mathrm{AFF}$, the rare adverse reaction resulting from long-term use of ALN, has recently become the subject of more attention from clinicians. Odvina et al. (20) were the first, to our knowledge, to report AFF from ALN use. They found that spontaneous nonvertebral fractures can occur in patients undergoing long-term use of ALN, even in the absence of obvious initiating trauma. Furthermore, these patients exhibited postoperative delayed union or nonunion. Since then, similar clinical cases have been reported at different medical centers $(21,22,23)$. According to the existing data, the incidence rate of AFF is $<4 \%$ in high femoral fractures, and most of the literatures related to AFF were case reports (as shown in Table 3).

Large, randomized, controlled trials have demonstrated that ALN therapy for 3-4 years is effective in reducing the risk of both nonvertebral and vertebral fractures in osteoporotic women (16). However, there is considerable controversy over the ideal duration of antiresorptive therapy in the light of reports regarding ALN-related AFF. Two randomized trials have been implemented to assess the efficacy of long-term use of ALN

\begin{tabular}{|c|c|c|c|c|c|c|c|c|c|}
\hline \multirow[b]{2}{*}{ Study or subgroup } & \multicolumn{2}{|c|}{ Experimental } & \multicolumn{2}{|c|}{ Control } & \multirow[b]{2}{*}{ Weight (\%) } & Odds ratio & \multicolumn{2}{|c|}{ Odds ratio } & \\
\hline & Events & Total & Events & Total & & M-H, Fixed, 95\% Cl & & ed, $95 \% \mathrm{Cl}$ & \\
\hline (13) & 22 & 178 & 27 & 356 & 5.9 & $1.72(0.95,3.11)$ & & 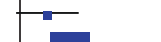 & \\
\hline (14) & 412 & 39567 & 637 & 158268 & 94.1 & $2.60(2.30,2.95)$ & & & \\
\hline Total $(95 \% \mathrm{Cl})$ & & 39745 & & 158624 & 100.0 & $2.55(2.26,2.88)$ & & 1 & \\
\hline Total events & 434 & & 664 & & & & & & \\
\hline Heterogeneity: $\chi^{2}=$ & $\mathrm{df}=1(P=$ & $=0.18) ;$ & $44 \%$ & & & 0.0 & 0.1 & 1 & 100 \\
\hline
\end{tabular}

Figure 3

The risk of AFF for patients using ALN for a long period ( $\geq 5$ years).

http://www.endocrineconnections.org
$\begin{array}{lr}\text { DOI: } 10.1530 / E C-14-0120 & 2015 \text { The authors } \\ \end{array}$

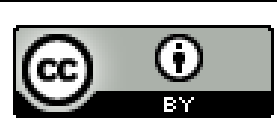

This work is licensed under a Creative Commons Attribution 3.0 Unported License. 
Table 3 Case studies of atypical femur fractures related to bisphosphonates.

\begin{tabular}{|c|c|c|c|}
\hline Reference & $\begin{array}{c}\text { AFF } \\
\text { number }\end{array}$ & $\begin{array}{c}\text { Average } \\
\text { treatment time }\end{array}$ & Average age \\
\hline$(20)$ & 7 & $5.6(3-8)$ & $60.0(49-68)$ \\
\hline$(28)$ & 9 & $4.2(2.5-5)$ & $66.9(55-82)$ \\
\hline (31) & 26 & $4.4(2-10)$ & $66.1(53-82)$ \\
\hline (32) & 12 & $7.3(5.5-9)$ & $70.4(55-83)$ \\
\hline (15) & 19 & 6.9 & 69.5 \\
\hline (33) & 2 & 7.0 & 72.0 \\
\hline (34) & 2 & 9.0 & 57.0 \\
\hline$(2)$ & 14 & $8.6(5-13)$ & $61.0(53-75)$ \\
\hline (35) & 3 & 9.0 & 66.5 \\
\hline (36) & 3 & $7.3(6-9)$ & $63.3(59-66)$ \\
\hline$(12)$ & 2 & 6.0 & 60.0 \\
\hline (37) & 16 & $4.5(2-7)$ & $68.0(53-92)$ \\
\hline (38) & 59 & $7.1(4-11)$ & 73.7 (67-85) \\
\hline
\end{tabular}

and the risk of fractures $(24,25)$. The results indicated that women are at a very high risk of clinical vertebral fractures when ALN was administered for more than 5 years. However, these trials were conducted in postmenopausal women, and therefore the results may not apply to younger women or to men.

To clarify the relationship between ALN and AFF, and provide credible advice for clinicians, we performed this meta-analysis. The results indicated that ALN administration did not increase the risk of AFF in short term (lower than 5 years), but there will be a risk of AFF $(P<0.05)$ with long-term ( $>5$ years) use of ALN.

The mechanisms of AFF are still unclear. Allen et al. (26) found that the bone micro-damage caused by ALN increased by more than sevenfold compared with the controls, with a concurrent bone mineral density decrease of $40 \%$, leading to increased ease of fracture. Results from another study also carried out by Allen (27) indicated that the long-term use of ALN could exert adverse effects on bone trabeculae and heterogeneous cross-linking of collagen, which will lead to bone fragility. The bone turnover and metabolism of patients with osteoporosis were abnormal, which represents a risk factor per se for the occurrence of AFF (28). Results from some studies have indicated that bone turnover could be suppressed excessively with long-term use of ALN, which will lead to excessive accumulation of bone micro-damage and the occurrence of AFF (21). In short, further animal experiments and clinical studies should be conducted to clarify the mechanism of AFF.

Considering the potential for the increased risk of AFF, we think that the use of ALN should not exceed 5 years, and it will be appropriate for patients to discontinue the use of ALN after 5 years. Moreover, most of the experts also recommend that the application of ALN should not exceed 5 years. AFF could heal themselves after discontinuation of ALN treatment, but can quickly recur when treatment resumes (23). Teriparatide (recombinant parathyroid peptide) is recommended for patients with AFF. In theory, teriparatide could promote favorable bone metabolism in patients with AFF; however, it is still unclear whether bone mineral density remains unchanged during the period of teriparatide treatment, or how long the antiresorptive drugs should be taken (29).

However, our research has some limitations. Of the five studies included, two were conducted in Denmark, one in Taiwan, while the others were conducted in America, leading to clinical heterogeneity in our study. Moreover, there is little data available regarding the longterm use of ALN and AFF, which may affect our results. In the future, multi-center prospective cohort studies using large sample sizes and various subgroups according to sex and age are needed.

The American Society for Bone and Mineral Research proposed that physicians should assess the condition of each patient individually because the optimal length of bisphosphonate therapy remains unknown and must be considered on a case-by-case basis (30). Objectively speaking, AFF is the only rare adverse reaction caused by ALN. As such, ALN is still a better option for patients with osteoporosis, and the benefits outweigh the possible risks for the majority of patients. Based on this approach, clinicians should not reject ALN outright, but should pay attention to its application, particularly the duration of administration.

\section{Conclusion}

In summary, this meta-analysis suggests that patients undergoing long-term treatment using ALN may be at an increased risk of AFF.

Declaration of interest

The authors declare that there is no conflict of interest that could be perceived as prejudicing the impartiality of the research reported.

\section{Funding}

This study was supported by the National Nature Science Foundation of China (30700387). 


\section{References}

$1 \mathrm{Ng}$ KW \& Martin TJ. New therapeutics for osteoporosis. Current Opinion in Pharmacology 2014 16C 58-63. (doi:10.1016/j.coph.2014. 03.004)

2 Capeci CM \& Tejwani NC. Bilateral low-energy simultaneous or sequential femoral fractures in patients on long-term alendronate therapy. Journal of Bone and Joint Surgery. American Volume 200991 2556-2561. (doi:10.2106/JBJS.H.01774)

3 Recker RR \& Saville PD. Intestinal absorption of disodium ethane-1hydroxy-1,1-diphosphonate (disodium etidronate) using a deconvolution technique. Toxicology and Applied Pharmacology 197324 580-589. (doi:10.1016/0041-008X(73)90219-6)

4 Russell RG, Watts NB, Ebetino FH \& Rogers MJ. Mechanisms of action of bisphosphonates: similarities and differences and their potential influence on clinical efficacy. Osteoporosis International 200819 733-759. (doi:10.1007/s00198-007-0540-8)

5 Cermak K, Shumelinsky F, Alexiou J \& Gebhart MJ. Case reports: subtrochanteric femoral stress fractures after prolonged alendronate therapy. Clinical Orthopaedics and Related Research 2010468 1991-1996. (doi:10.1007/s11999-009-1192-0)

6 Cao Y, Mori S, Mashiba T, Westmore MS, Ma L, Sato M, Akiyama T, Shi L, Komatsubara S, Miyamoto K et al. Raloxifene, estrogen, and alendronate affect the processes of fracture repair differently in ovariectomized rats. Journal of Bone and Mineral Research 200217 2237-2246. (doi:10.1359/jbmr.2002.17.12.2237)

7 Tonino RP, Meunier PJ, Emkey R, Rodriguez-Portales JA, Menkes CJ, Wasnich RD, Bone HG, Santora AC, Wu M, Desai R et al. Skeletal benefits of alendronate: 7-year treatment of postmenopausal osteoporotic women. Phase III Osteoporosis Treatment Study Group. Journal of Clinical Endocrinology and Metabolism 200085 3109-3115. (doi:10.1210/jcem.85.9.6777)

8 Fleisch H, Russell RG \& Francis MD. Diphosphonates inhibit hydroxyapatite dissolution in vitro and bone resorption in tissue culture and in vivo. Science 1969165 1262-1264. (doi:10.1126/science.165. 3899.1262)

9 Rogers MJ. New insights into the molecular mechanisms of action of bisphosphonates. Current Pharmaceutical Design 20039 2643-2658. (doi:10.2174/1381612033453640)

10 Pols HA, Felsenberg D, Hanley DA, Stepan J, Munoz-Torres M, Wilkin TJ, Qin-sheng G, Galich AM, Vandormael K, Yates AJ et al. Multinational, placebo-controlled, randomized trial of the effects of alendronate on bone density and fracture risk in postmenopausal women with low bone mass: results of the FOSIT study. Fosamax International Trial Study Group. Osteoporosis International 19999 461-468. (doi:10.1007/PL00004171)

11 Bone HG, Hosking D, Devogelaer JP, Tucci JR, Emkey RD, Tonino RP, Rodriguez-Portales JA, Downs RW, Gupta J, Santora AC et al. Ten years' experience with alendronate for osteoporosis in postmenopausal women. New England Journal of Medicine 2004350 1189-1199. (doi:10.1056/NEJMoa030897)

12 Edwards MH, McCrae FC \& Young-Min SA. Alendronate-related femoral diaphysis fracture - what should be done to predict and prevent subsequent fracture of the contralateral side? Osteoporosis International 201021 701-703. (doi:10.1007/s00198-009-0986-y)

13 Abrahamsen B, Eiken P \& Eastell R. Subtrochanteric and diaphyseal femur fractures in patients treated with alendronate: a register-based national cohort study. Journal of Bone and Mineral Research 200924 1095-1102. (doi:10.1359/jbmr.081247)

14 Abrahamsen B, Eiken P \& Eastell R. Cumulative alendronate dose and the long-term absolute risk of subtrochanteric and diaphyseal femur fractures: a register-based national cohort analysis. Journal of Clinical Endocrinology and Metabolism 201095 5258-5265. (doi:10.1210/ jc.2010-1571)

15 Neviaser AS, Lane JM, Lenart BA, Edobor-Osula F \& Lorich DG. Low-energy femoral shaft fractures associated with alendronate use.
Journal of Orthopaedic Trauma 200822 346-350. (doi:10.1097/BOT. 0b013e318172841c)

16 Black DM, Kelly MP, Genant HK, Palermo L, Eastell R, Bucci-Rechtweg C, Cauley J, Leung PC, Boonen S, Santora A et al. Bisphosphonates and fractures of the subtrochanteric or diaphyseal femur. New England Journal of Medicine 2010362 1761-1771. (doi:10.1056/NEJMoa1001086)

17 Hsiao FY, Huang WF, Chen YM, Wen YW, Kao YH, Chen LK \& Tsai YW. Hip and subtrochanteric or diaphyseal femoral fractures in alendronate users: a 10-year, nationwide retrospective cohort study in Taiwanese women. Clinical Therapeutics 201133 1659-1667. (doi:10.1016/ j.clinthera.2011.09.006)

18 Drake MT, Clarke BL \& Khosla S. Bisphosphonates: mechanism of action and role in clinical practice. Mayo Clinic Proceedings $2008 \mathbf{8 3}$ 1032-1045. (doi:10.4065/83.9.1032)

19 Mashiba T, Hirano T, Turner CH, Forwood MR, Johnston CC \& Burr DB. Suppressed bone turnover by bisphosphonates increases microdamage accumulation and reduces some biomechanical properties in dog rib. Journal of Bone and Mineral Research 200015 613-620. (doi:10.1359/ jbmr.2000.15.4.613)

20 Odvina CV, Zerwekh JE, Rao DS, Maalouf N, Gottschalk FA \& Pak CY. Severely suppressed bone turnover: a potential complication of alendronate therapy. Journal of Clinical Endocrinology and Metabolism 200590 1294-1301. (doi:10.1210/jc.2004-0952)

21 Jamal SA, Dion N \& Ste-Marie LG. Atypical femoral fractures and bone turnover. New England Journal of Medicine 2011365 1261-1262. (doi:10.1056/NEJMc1107029)

22 Bjorgul K \& Reigstad A. Atypical fracture of the ulna associated with alendronate use. Acta Orthopaedica 201182 761-763. (doi:10.3109/ 17453674.2011.636676)

23 Puah KL \& Tan MH. Bisphosphonate-associated atypical fracture of the femur: Spontaneous healing with drug holiday and re-appearance after resumed drug therapy with bilateral simultaneous displaced fractures - a case report. Acta Orthopaedica 201182 380-382. (doi:10.3109/17453674.2011.581267)

24 Black DM, Schwartz AV, Ensrud KE, Cauley JA, Levis S, Quandt SA Satterfield S, Wallace RB, Bauer DC, Palermo L et al. Effects of continuing or stopping alendronate after 5 years of treatment: the Fracture Intervention Trial Long-term Extension (FLEX): a randomized trial. Journal of the American Medical Association 2006296 2927-2938. (doi:10.1001/jama.296.24.2927)

25 Black DM, Reid IR, Boonen S, Bucci-Rechtweg C, Cauley JA, Cosman F, Cummings SR, Hue TF, Lippuner K, Lakatos P et al. The effect of 3 versus 6 years of zoledronic acid treatment of osteoporosis: a randomized extension to the HORIZON-Pivotal Fracture Trial (PFT). Journal of Bone and Mineral Research 201227 243-254. (doi:10.1002/jbmr.1494)

26 Allen MR, Iwata K, Phipps R \& Burr DB. Alterations in canine vertebral bone turnover, microdamage accumulation, and biomechanical properties following 1-year treatment with clinical treatment doses of risedronate or alendronate. Bone 200639 872-879. (doi:10.1016/ j.bone.2006.04.028)

27 Allen MR. Skeletal accumulation of bisphosphonates: implications for osteoporosis treatment. Expert Opinion on Drug Metabolism \& Toxicology 20084 1371-1378. (doi:10.1517/17425255.4.11.1371)

28 Goh SK, Yang KY, Koh JS, Wong MK, Chua SY, Chua DT \& Howe TS. Subtrochanteric insufficiency fractures in patients on alendronate therapy: a caution. Journal of Bone and Joint Surgery. British Volume 2007 89 349-353. (doi:10.1302/0301-620X.89B3.18146)

29 Sellmeyer DE. Atypical fractures as a potential complication of long-term bisphosphonate therapy. Journal of the American Medical Association 2010304 1480-1484. (doi:10.1001/jama.2010.1360)

30 Shane E, Burr D, Abrahamsen B, Adler RA, Brown TD, Cheung AM, Cosman F, Curtis JR, Dell R, Dempster DW et al. Atypical subtrochanteric and diaphyseal femoral fractures: second report of a task force of the american society for bone and mineral research. Journal of Bone and Mineral Research 201429 1-23. (doi:10.1002/jbmr.1998)

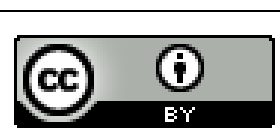


31 Kwek EB, Goh SK, Koh JS, Png MA \& Howe TS. An emerging pattern of subtrochanteric stress fractures: a long-term complication of alendronate therapy? Injury 200839 224-231. (doi:10.1016/j.injury.2007.08.036)

32 Lenart BA, Lorich DG \& Lane JM. Atypical fractures of the femoral diaphysis in postmenopausal women taking alendronate. New England Journal of Medicine 2008358 1304-1306. (doi:10.1056/ NEJMc0707493

33 Sayed-Noor AS \& Sjoden GO. Case reports: two femoral insufficiency fractures after long-term alendronate therapy. Clinical Orthopaedics and Related Research 2009467 1921-1926. (doi:10.1007/s11999. 009-0725-x)

34 Aspenberg P. Bisphosphonate-induced fractures: nature strikes back? Acta Orthopaedica 200879 459-460. (doi:10.1080/1745367071 0015427)
35 Sayed-Noor AS \& Sjoden GO. Subtrochanteric displaced insufficiency fracture after long-term alendronate therapy - a case report. Acta Orthopaedica 200879 565-567. (doi:10.1080/174536707 10015580)

36 Schneider JP. Bisphosphonates and low-impact femoral fractures: current evidence on alendronate-fracture risk. Geriatrics 200964 18-23.

37 Koh JS, Goh SK, Png MA, Kwek EB \& Howe TS. Femoral cortical stress lesions in long-term bisphosphonate therapy: a herald of impending fracture? Journal of Orthopaedic Trauma 201024 75-81. (doi:10.1097/ BOT.0b013e3181b6499b)

38 Isaacs JD, Shidiak L, Harris IA \& Szomor ZL. Femoral insufficiency fractures associated with prolonged bisphosphonate therapy. Clinical Orthopaedics and Related Research 2010468 3384-3392. (doi:10.1007/ s11999-010-1535-x)

Received in final form 16 December 2014 Accepted 22 December 2014
(C) 2015 The authors Published by Bioscientifica Ltd

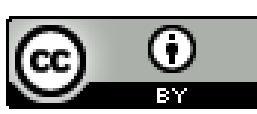

This work is licensed under a Creative Commons Attribution 3.0 Unported License. 